\title{
The seed bank of livestock dung in the Qilian Mountain grassland: a potential resource for vegetation renewal
}

\author{
Shulin Wang ${ }^{1}$ and Fujiang $\mathrm{Hou}^{2}$ \\ ${ }^{1}$ Affiliation not available \\ ${ }^{2}$ Lanzhou University
}

April 28, 2020

\begin{abstract}
The Qilian Mountain Grassland is an important animal husbandry production base in northwestern China. Horses, cattle and sheep are the main livestock, which are widely distributed in the desert grassland and alpine meadow around the Qilian Mountains. Grazing livestock produce large amounts of feces, and the germinated seeds in the feces constitute the dung seed bank of the grassland. Research on the size, composition and distribution of livestock manure seed bank in the Qilian Mountain grassland may provide a deeper understanding of the interaction between grass and livestock and help inform comprehensive management practices for grazing livestock. In mid-October 2018, we collected the dung of horses, cattle and sheep in the alpine meadows and desert grasslands of the Qilian Mountains and measured the composition and size of the dung seed bank by the greenhouse germination method. The dominant species of seeds in the dung collection site were also collected to determine the relationship between the size and composition of the dung seed bank and the seed traits (mass and shape). A total of 30 different species of seedlings germinated from the dung of the three livestock. Of these, 22 species ( $73 \%$ of total) were perennial. The seedling densities (g-1 dung) of horse, cattle and sheep were 5.23, 3.27 and 0.72 , respectively. The species richness, species diversity, and the Jaccard coefficients of similarity between dung seedling and aboveground vegetation of horse dung were significantly greater than those of cattle and sheep $(\mathrm{P}<0.05)$. Regression analyses indicated that medium-sized (10-30 mg) and spherical (0.04-0.10 shape index) seeds had the greatest germination potential. Our study suggests that, of the three livestock species tested, the horse dung seed bank contributes most to grassland recovery and restoration of the Qilian Mountains.
\end{abstract}

\section{Hosted file}

Manuscript. docx available at https://authorea.com/users/310107/articles/440910-the-seed-bankof-livestock-dung-in-the-qilian-mountain-grassland-a-potential-resource-for-vegetation-renewal

\section{Hosted file}

Figures.docx available at https://authorea.com/users/310107/articles/440910-the-seed-bank-oflivestock-dung-in-the-qilian-mountain-grassland-a-potential-resource-for-vegetation-renewal 